\title{
MORTALITY TRENDS IN CARCINOMA OF THE CERVIX UTERI
}

\author{
Jose L. CAMPos* \\ Department of Radiology (Alice Crocker Lloyd Radiation Therapy Center), \\ University of Michigan, Ann Arbor, Michigan 48104, U.S.A. \\ (Received 31 July 1970; in revised form 28 January 1971; \\ further revised 30 July 1971)
}

REvIEW of the cancer deaths among 1202 staged cases of carcinoma of the cervix treated at the Radiation Therapy Center of the University of Michigan from 1941 through 1964 indicates that each clinical stage is endowed with its own singular mortality trend. The cancer mortality trend of each stage is in our experience independent of the 5-yr survival rate. Improved survival obtained through the use of more effective therapeutic methods has not altered the mortality trend of each stage. We have also obtained evidence that when the logarithm of survival time of the patients destined to die of cancer is plotted against time the line of regression is straight. These observations are based on examination of the following case material.

\section{CASE MATERIAL}

This report includes all patients who began treatment for carcinoma of the cervix uteri at the Radiation Therapy Center of the University of Michigan between January 1941 and December 1964. Some stage IV cases did not conclude the prescribed treatment because of the deterioration that such advanced degree of disease produces. A few other patients died during treatment due to intercurrent disease. Among the 1202 cases that constitute the basis of this report there are both squamous cell and adenocarcinomas but all unclassified and previously treated cases have been excluded. All patients have been observed for at least $5 \mathrm{yr}$ after treatment or for as long as they have lived and we have information regarding the fate of all cases.

\section{STAGING}

Carcinoma of the cervix uteri is staged in our institution according to the International Classification [1]. The act of staging is carried out in a joint Conference of the Department of Gynecology and the Radiation I herapy Center. The patients are examined by at least two, very often three, senior members of those departments and staged by agreement.

*Reprint Address: Radiation Therapy Center, University Hospital, Ann Arbor, Michigan 48104, U.S.A. 


\section{DEFINITIONS}

This paper is concerned with the cancer mortality trend of the stages I-IV of carcinoma of the cervix uteri. By mortality trend we mean the successive accumulation of deaths, specifically cancer deaths, during the first five years after treatment. By cancer death we mean the demise of a patient in whom cancer of the cervix was present. By intercurrent death we mean that at the time of death a former patient of carcinoma of the cervix was not known to harbor that tumor. The relative youth of most patients with carcinoma of the cervix uteri prevents the accumulation of many deaths due to intercurrent disease.

\section{TREATMENT}

Primary treatment of carcinoma of the cervix is intracavitary radium application but a very important adjunct to it is external irradiation. Most of our patients have been treated with a combination of both. The intensity of radium therapy began to increase at the end of the 1941-1950 decade. This intensification of the treatment was gradual so that no date can be chosen that separates in this respect one treatment period from another. External irradiation, on the contrary, changed abruptly when Cobalt 60 radiation became available in 1956. The tumor dose that can be delivered with this type of radiation is much higher than with the previously employed deep $\mathrm{X}$-ray therapy and the complications are fewer. The combination of higher intensity radium treatment and improved external irradiation is clearly marked in our experience by more favorable 5-yr survival rates. Our material can thereby be divided into two groups: (a) patients treated between 1941 through 1955 and (b) patients treated between 1956 and 1964.

\section{CUMULATIVE MORTALITY}

The distribution of cases by stage and treatment period is shown in Table 1. It also indicates the overall crude 5-yr survival rate and for two treatment periods. The distribution of cases by age groups for the periods with different survival rates is very similar. Stage III patients have a tendency to be slightly older and this difference has been more marked during the period 1956-1964.

Table 1. Distribution of Cases by stage AND PERIOD

\begin{tabular}{lrrrr}
\hline Stage & I & II & III & IV \\
1941-1955 & 232 & 350 & 256 & 53 \\
1956-1964 & 116 & 106 & 83 & 6 \\
Total & 348 & 456 & 339 & 59
\end{tabular}

Overall crude 5-yr survival rate and for two treatment periods

\begin{tabular}{lcccr} 
Stage & I & II & III & IV \\
$1941-1955$ & $69.8 \%$ & $57.1 \%$ & $22.6 \%$ & $7.5 \%$ \\
$1956-1964$ & $77.5 \%$ & $68.8 \%$ & $43.3 \%$ & $16.6 \%$ \\
$1941-1964$ & $72.4 \%$ & $59.8 \%$ & $27.7 \%$ & $8.5 \%$ \\
$\chi^{2}$ value for difference in survival between periods 25.82 & $P$ & $<0.001$ \\
\hline
\end{tabular}

The data on cumulative cancer mortality from carcinoma of the cervix uteri are presented in Tables 2-4 and displayed in Fig. 1 for the whole period of interest and for the two periods for which we have found different 5-yr survival rates. We do not 
present a comparative table for stage IV because the number of patients during the period 1956-1964 is very small. Among our cases 75 per cent of all cancer deaths from stage IV occur during the first post-treatment year and by the third post-treatment year all patients that are to die of the disease during the first 60 post-treatment months will have done so.

Table 2. Cumulative mortality-Stage I

\begin{tabular}{|c|c|c|c|c|c|c|}
\hline \multirow[b]{2}{*}{ Yr } & \multicolumn{2}{|c|}{ All cases } & \multicolumn{2}{|c|}{ 1941-1955 } & \multicolumn{2}{|c|}{$1956-1964$} \\
\hline & $\begin{array}{l}\text { No. of } \\
\text { deaths }\end{array}$ & Fraction & $\begin{array}{l}\text { No. of } \\
\text { deaths }\end{array}$ & Fraction & $\begin{array}{l}\text { No. of } \\
\text { deaths }\end{array}$ & Fraction \\
\hline 1 & 12 & 0.151 & 8 & 0.134 & 4 & 0.222 \\
\hline 2 & 35 & 0.443 & 26 & 0.426 & 9 & 0.500 \\
\hline 3 & 59 & 0.746 & 46 & 0.754 & 13 & 0.722 \\
\hline 4 & 71 & 0.898 & 55 & 0.901 & 16 & 0.888 \\
\hline 5 & 79 & 1.000 & 61 & 1.000 & 18 & 1.000 \\
\hline
\end{tabular}

TAble 3. Cumulative MorTality-STage II

\begin{tabular}{|c|c|c|c|c|c|c|}
\hline \multirow[b]{2}{*}{ Yr } & \multicolumn{2}{|c|}{ All cases } & \multicolumn{2}{|c|}{$1941-1955$} & \multicolumn{2}{|c|}{$1956-1964$} \\
\hline & $\begin{array}{l}\text { No. of } \\
\text { deaths }\end{array}$ & Fraction & $\begin{array}{l}\text { No. of } \\
\text { deaths }\end{array}$ & Fraction & $\begin{array}{l}\text { No. of } \\
\text { deaths }\end{array}$ & Fraction \\
\hline 1 & 50 & 0.287 & 41 & 0.286 & 9 & 0.290 \\
\hline 2 & 105 & 0.603 & 86 & 0.607 & 19 & 0.612 \\
\hline 3 & 136 & 0.787 & 110 & 0.769 & 26 & 0.838 \\
\hline 4 & 166 & 0.954 & 137 & 0.976 & 29 & 0.935 \\
\hline 5 & 174 & 1.000 & 143 & 1.000 & 31 & 1.000 \\
\hline
\end{tabular}

Table 4. Cumulative mortality-Stage $11 \mathrm{I}$

\begin{tabular}{|c|c|c|c|c|c|c|}
\hline \multirow[b]{2}{*}{$\mathrm{Yr}$} & \multicolumn{2}{|c|}{ All cases } & \multicolumn{2}{|c|}{$1941-1955$} & \multicolumn{2}{|c|}{$1956-1964$} \\
\hline & $\begin{array}{l}\text { No. of } \\
\text { deaths }\end{array}$ & Fraction & $\begin{array}{l}\text { No. of } \\
\text { deaths }\end{array}$ & Fraction & $\begin{array}{l}\text { No. of } \\
\text { deaths }\end{array}$ & Fraction \\
\hline 1 & 107 & 0.449 & 89 & 0.458 & 18 & 0.409 \\
\hline 2 & 174 & 0.731 & 144 & 0.742 & 30 & 0.681 \\
\hline 3 & 207 & 0.869 & 167 & 0.860 & 40 & 0.909 \\
\hline 4 & 225 & 0.945 & 181 & 0.932 & 44 & 1.000 \\
\hline 5 & 238 & 1.000 & 194 & 1.000 & 44 & 1.000 \\
\hline
\end{tabular}

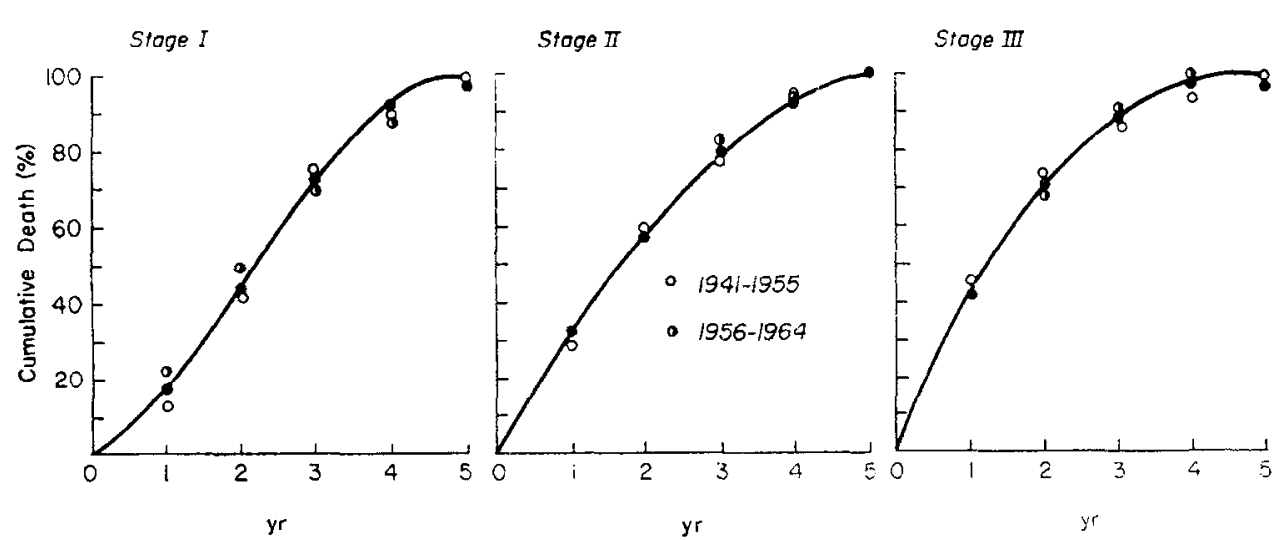

FIG. 1. Display of the data of Tables 2-4. The regression line has been fitted through parabolic equations. 
The parallelism of the mortality trends between periods with different 5-yr survival rates indicates that the form of the mortality trend is strongly related to the stage of the disease.

\section{REVIEW OF THE MEDICAL LITERATURE}

Our finding that each stage of carcinoma of the cervix uteri is endowed with its own mortality trend is supported by review of the medical literature. We have tabulated mortality data from several sources and we have divided them into two groups. Table 5 presents the cumulative cancer mortality from two institutions that report results of treatment in the period 1922-1934 [2,3]. Table 6 presents cumulative cancer mortality from various sources $[2,4-6]$ among cases treated between 1932 and 1954 and compares them with our own results. The tables have been assembled from explicit information offered by the authors except in the case of Manchester [4] whose data have been read out of graphs adjusted for age. The first-year mortality in stage III from Manchester is distinctly out of step with the rest. However, from the second year on, the mortality trend is in line with the data from the other institutions.

TABle 5. Cumulative CANCER MORTAlity From tWo CENTERS REPORTING RADIUM THERAPY ONLY. YR 1922-1934

\begin{tabular}{lcccccr}
\hline & \multicolumn{2}{c}{ Stage I } & \multicolumn{2}{c}{ Stage II } & \multicolumn{2}{c}{ Stage III } \\
& $(2)$ & $(3)$ & $(2)$ & $(3)$ & $(2)$ & $(3)$ \\
No. of cases & 164 & 47 & 596 & 185 & 614 & 418 \\
Fraction dead & & & & & & \\
$\quad$ 1st yr & 0.250 & 0.400 & 0.312 & 0.293 & 0.514 & 0.500 \\
2nd yr & 0.550 & 0.650 & 0.681 & 0.655 & 0.824 & 0.779 \\
3rd yr & 0.750 & 0.700 & 0.862 & 0.818 & 0.935 & 0.923 \\
4th yr & 0.950 & 0.750 & 0.928 & 0.922 & 0.985 & 0.964 \\
$\quad$ 5th yr & 1.000 & 1.000 & 1.000 & 1.000 & 1.000 & 1.000 \\
No. of cancer deaths & 60 & 20 & 349 & 116 & 484 & 340 \\
5-yr survival & $57.3 \% *$ & $57.5 \% *$ & $36.7 \% *$ & $37.2 \% *$ & $17.8 \% *$ & $18.7 \% *$ \\
\hline
\end{tabular}

*Crude

We have omitted the data for stage I from Sheffield because the number of deaths was small.

In Table 7 we have pooled all the data from Table 6, added stage IV data and obtained general mortality trends.

Slight variations are present in the mortality trends as reported from various sources. However the differences between stages are so great that they overshadow the disparities within a stage among several institutions. The steadiness of stage II is notable. In stage III we find the discordant note of the first year mortality from Manchester. This displacement towards earlier death was not kept after the second year for the mortality for the second, third, fourth and fifth years is concordant with the rest.

The group of cases in stage I reported by Sorensen (Table 5, second column) behaves in a manner very different from that of all other sources. When the survival of this group of cases is plotted on logarithmic probabilistic paper as Boag suggested [7] it does not follow a straight line. 
Table 6. Mortality trends, By STAGe, from Varjous Sources. YR 1932-1964

\begin{tabular}{|c|c|c|c|c|c|}
\hline \multicolumn{6}{|c|}{ Stage I } \\
\hline & $\begin{array}{l}\text { Manchester } \\
\text { (4) }\end{array}$ & $\begin{array}{c}\text { Copenhagen } \\
(6)\end{array}$ & $\begin{array}{l}\text { Sheffield } \\
\text { (5) }\end{array}$ & $\begin{array}{l}\text { Stockholm } \\
\text { (2) }\end{array}$ & Ann Arbor \\
\hline No. of cases & 262 & 49 & 50 & 268 & 348 \\
\hline $\begin{array}{l}\text { Fraction dead } \\
\text { 1st yr } \\
\text { 2nd yr } \\
\text { 3rd yr } \\
\text { 4th yr } \\
\text { 5th yr }\end{array}$ & $\begin{array}{l}0.142 \\
0.428 \\
0.714 \\
0.928 \\
1.000\end{array}$ & $\begin{array}{l}0.183 \\
0.440 \\
0.688 \\
0.810 \\
1.000\end{array}$ & $\begin{array}{l}- \\
- \\
-\end{array}$ & $\begin{array}{l}0.212 \\
0.651 \\
0.818 \\
0.924 \\
1.000\end{array}$ & $\begin{array}{l}0.151 \\
0.443 \\
0.746 \\
0.898 \\
1.000\end{array}$ \\
\hline No. of cancer deaths & 73 & 15 & 11 & 66 & 79 \\
\hline 5-yr survival rate & $72 \% \dagger$ & $67.3 \% *$ & $69 \% *$ & $70.1 \% *$ & $72.4 \% *$ \\
\hline \multicolumn{6}{|c|}{ Stage II } \\
\hline No. of cases & 1812 & 224 & 203 & 1380 & 456 \\
\hline $\begin{array}{l}\text { Fraction dead } \\
\text { 1st yr } \\
\text { 2nd yr } \\
\text { 3rd yr } \\
\text { 4th yr } \\
\text { 5th yr }\end{array}$ & $\begin{array}{l}0.291 \\
0.645 \\
0.791 \\
0.937 \\
1.000\end{array}$ & $\begin{array}{l}0.259 \\
0.659 \\
0.798 \\
0.954 \\
1.000\end{array}$ & $\begin{array}{l}0.291 \\
0.604 \\
0.791 \\
0.895 \\
1.000\end{array}$ & $\begin{array}{l}0.333 \\
0.661 \\
0.848 \\
0.948 \\
1.000\end{array}$ & $\begin{array}{l}0.287 \\
0.603 \\
0.787 \\
0.954 \\
1.000\end{array}$ \\
\hline No. of cancer deaths & 869 & 101 & 97 & 639 & 174 \\
\hline 5-yr survival rate & $52 \% \dagger$ & $51.8 \% *$ & $49 \%$ & $49.5 \% *$ & $59.8 \% *$ \\
\hline \multicolumn{6}{|c|}{ Stage III } \\
\hline No. of cases & 1451 & 142 & 205 & 779 & 339 \\
\hline $\begin{array}{l}\text { Fraction dead } \\
\text { 1st yr } \\
\text { 2nd yr } \\
\text { 3rd yr } \\
\text { 4th yr } \\
\text { 5th yr }\end{array}$ & $\begin{array}{l}0.606 \\
0.757 \\
0.878 \\
0.939 \\
1.000\end{array}$ & $\begin{array}{l}0.450 \\
0.703 \\
0.867 \\
0.945 \\
1.000\end{array}$ & $\begin{array}{l}0.507 \\
0.802 \\
0.887 \\
0.971 \\
1.000\end{array}$ & $\begin{array}{l}0.508 \\
0.832 \\
0.938 \\
0.980 \\
1.000\end{array}$ & $\begin{array}{l}0.449 \\
0.731 \\
0.869 \\
0.945 \\
1.000\end{array}$ \\
\hline No. of cancer deaths & 958 & 89 & 143 & 568 & 238 \\
\hline 5-yr survival rate & $34 \% \dagger$ & $35.9 \% *$ & $30 \% *$ & $23.8 \% *$ & $27.7 \% *$ \\
\hline
\end{tabular}

${ }^{*}$ Crude

†Age adjusted

Table 7. Cumulative 5-yr Cancer mortality. General computation

\begin{tabular}{lcccc}
\hline Stage & I & II & III & IV \\
No. of cases & 978 & 4075 & 2916 & 1262 \\
Fraction dead & & & & \\
1st yr & 0.168 & 0.303 & 0.545 & 0.758 \\
2nd yr & 0.511 & 0.645 & 0.776 & 0.904 \\
3rd yr & 0.759 & 0.810 & 0.894 & 0.975 \\
4th yr & 0.913 & 0.938 & 0.954 & 0.989 \\
5th yr & 1.000 & 1.000 & 1.000 & 1.000 \\
No. of cancer deaths & 244 & 1880 & 1995 & 1125 \\
\hline
\end{tabular}

THE EXPONENTIAL FUNCTION

Inspection of the trend of cumulative death in stage III cases (Fig. 1) shows that approximately one half of the deaths that are to occur during the first five post- 
treatment years have occurred during the first year after treatment. Half as many occur during the second. This suggests that the process of attrition of the population destined to die of cancer may be exponential. We have plotted the logarithm of duration of survival for patients that have died of cancer against time in Figs. 2 and 3. For stage I ( 76 deaths) and stage II (160 deaths) the computation has been restricted to data from the period $1941-1959$, for these stages show a sizable mortality after the 60th post treatment month and $10 \mathrm{yr}$ follow-up is mandatory. For stages III and IV we have used only 5-yr follow-up data. Among all the stage III patients treated between 1941 and 1959 only 5 cancer deaths have occurred between the 60th and 120th months. In stage IV we have no instance of cancer death between the 3rd and 10th yr.

The survival has been plotted by bimesters and as having been registered midway in the 2 month period except for the deaths occurring after $5 \mathrm{yr}$. The latter have been plotted whenever they took place.

The resemblance of these curves to those of cell survival after irradiation is uncanny. It will be noted that the straight portion of the regression line does not cross the ordinate at level 1.00 in stages I-III. The displacement of the straight segment of the curves towards the right is present in systems in which, it is postulated, there is a redundancy of targets where death occurs, according to this view, when several targets are neutralized either simultaneously or consecutively. When the neutralization of a single target is enough to cause death the exponential regression line crosses the ordinate at level 1.00 [8]. The displacement of the straight segment towards the right indicates a multiplicity of targets. An index of this multiplicity is the extrapolation number. The latter is obtained by extrapolating back the straight segment of the curve and reading the value of its intersection with the ordinate.

Because of the displacement of the regression line towards the right a simple exponential would not fit the data for stages I-III. The equation

$$
S=1-\left(1-e^{-k t}\right)^{n}
$$

does. $\mathrm{S}$ is the proportion of doomed survivors alive at a given time $t$, $\mathrm{e}$ is the base of natural logarithms and $\mathbf{k}$ is a constant identical in function with a decay constant. Note that the expression $\left(1-\mathrm{e}^{-\mathrm{kt}}\right)$ indicating the proportion of patients dead at time $t$ is raised to a power $n$ (the extrapolation number), in order to take into account the displacement of the curve towards the right.

The curves of Figs. 2 and 3 have been fitted by sight. The constant $k$ has the dimensions months ${ }^{-1}$. It has been obtained by dividing 0.693 by the half lethality period, the latter being read out directly from the graphs.

The information available regarding the trend of mortality during the first posttreatment year is scanty. We have compared our data with Sorensen's [3] and the fit is extremely close for stages II-IV. Sorensen's stage I, as can be seen in table 5, behaves erratically. Besides the presence of the extrapolation number the curves for each stage show singular slopes. The difference in slope between stages I and II, if it exists at all, is small but it is clear that the early and late stages are differentiated by widely different slopes. The data of Table 7 follow the exponential regression lines very well when the proportion of patients dead by the 5 th $\mathrm{yr}$ is assumed to be equivalent to the expected proportion dead according to our curves. 


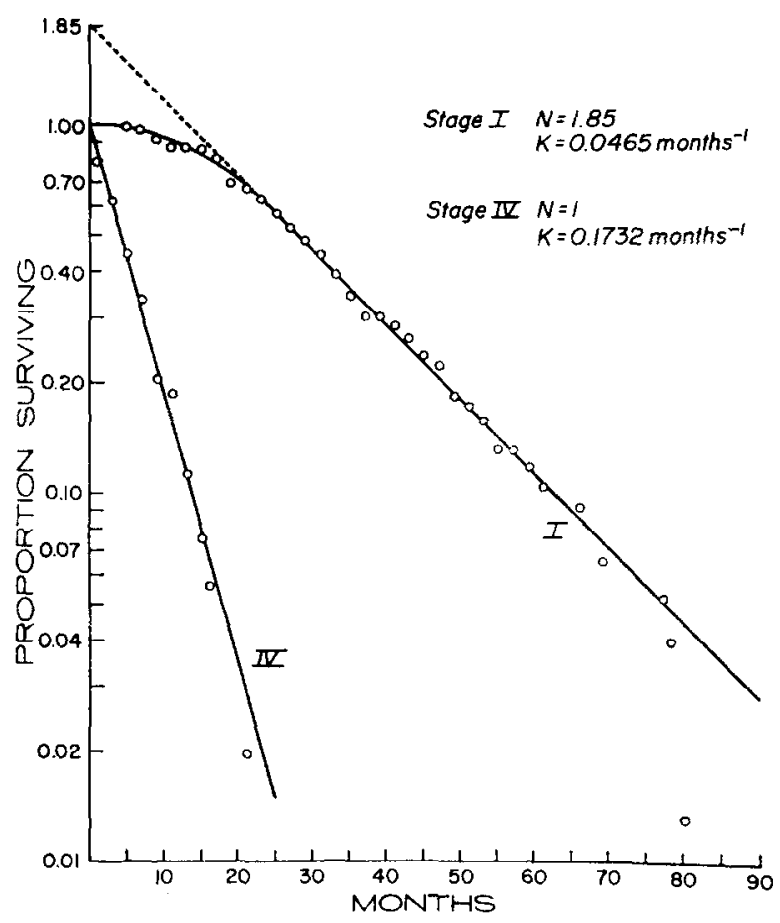

FIG. 2. Survival of patients destined to die of cancer. Stages I and IV.

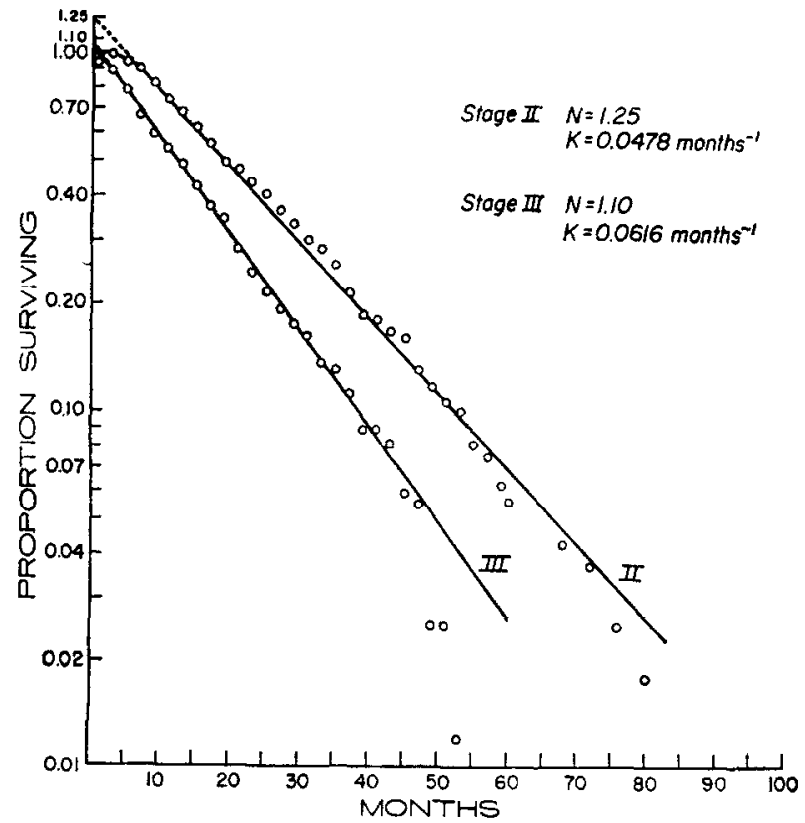

Fro. 3. Survival of patients destined to die of cancer. Stages II and III. 


\section{DISCUSSION}

We have shown that each clinical stage of carcinoma of the cervix uteri has a singular trend of mortality and that the form of the trend is independent of $5 \mathrm{yr}$ survival rates. We have defined each stage in terms of an exponential function and we have found evidence of the medical literature that supports the view that the trends as described have validity beyond the experience of the University of Michigan.

We have noted a similarity between the survival of failures of treatment and the cell survival curves of radiobiology. We may postulate that tumors have to grow along the axis of time until they reach such size after which death becomes exponential [9]. The extrapolation number is greatest in stage I and reaches unity in stage IV. Another feature of interest is that the slope for the survival of doomed cases is greatest for the advanced cases and less steep for earlier ones. Myers et al [10] have shown that in carcinoma of the breast the mortality is exponential but when cases are grouped according to the presence and absence of favorable prognostic signs the slope of the line of regression varies. The slope is steeper in the groups containing more unfavorable prognostic signs.

Another observation of interest is that cases of carcinoma of the cervix that are not cured are not grossly affected by treatment. Despite great improvements in the 5-yr survival rate the sequence of death has not shown major change. This finding though upsetting to the intuition cannot be overlooked. A more successful treatment does not thereby imply greater palliation in unsuccessful cases, for we have observed trends of mortality that are steady for each stage despite variation in the 5-yr survival rate.

Boag has shown that the distribution of the logarithm of survival of treatment failures is normal. His observation has been confirmed by others [3, 11]. Berg upon critically reviewing the validity of the lognormal model concluded that often the fitting of models to data is poor particularly in the early post-treatment period. He mentions that the exponential model shows considerable deviation from the actuality of mortality. We have pointed out earlier that no simple exponential will fit the data when the curve is displaced towards the right (when the curve has a shoulder). The extrapolation number together with variations in slope are characteristics of the stages of carcinoma of the cervix uteri. Upon the framework of exponential attrition of the non-cured population other attrition forces superimpose themselves on the remaining cured population [13]. The result is a general survival curve of greater complexity than a simple exponential.

\section{REFERENCES}

1. Kottmeier HL: Annual report on the results of treatment in carcinoma of the uterus and vagina, 14th volume. Stockholm, Sweden 1967, p 16

2. Lindell A: Carcinoma of the uterine cervix. Incidence and influence of age. Acta Radiol Supp, 92, 1952

3. Sorensen B: Late results of radium therapy in cervical carcinoma. Acta Radiol Supp, 169, 1958

4. Easson EC, Russell MH: The curability of cancer in various sites. Baltimore, Williams and Wilkins Company, 1968

5. Blomfield GW: The treatment of cancer of the uterine cervix by radium and X-ray therapy. Brit J Radiol 34: 755-768, 1961

6. Truelsen F: Cancer of the uterine cervix. London, H K Lewis and Co Ltd, p 138, 1949

7. Boag JW: The presentation and analysis of the results of radiotherapy. Brit J Radiol 21: 128-138, 1948 
8. Cohen L: Radiation response and recovery, radiobiological principles and their relation to clinical practice. Chapter 6. Biological Basis of Radiation Therapy. (E Schwartz, Ed). Philadelphia, J B Lippincott, 1966

9. Jones HB: Demographic consideration of the cancer problem. Trans NY Acad Sci 18: 298-333, 1956

10. Myers MH, Axtell LM, Zelen M: The use of prognostic factors in predicting survival for breast cancer patients. J Chron Dis 19: 923-933, 1966

11. Nolan JF, DuSault L: Radiation Treatment of cancer of the cervix uteri. Amer J Roentgenol 65 : 709-714, 1951

12. Berg JW: 'The distribution of cancer deaths in time. Brit J Cancer 19:695-711, 1965

13. Berkson J, Gage RP: Survival curve for cancer patients following treatment. J Amer Stat Assoc 47: 501-515, 1952 